ken i Flandern, bl.a. Hooge Crater og Käthe Kollwitz Tower. Den fjerde dag kørte vi til Sedan i Frankrig, hvor vi overnattede på La Chateau fort Sedan, en ombygget gammel middelalderborg. Den femte dag påbegyndtes hjemturen gennem Belgien og Luxembourg mod Køln, hvor der overnattedes på hote Mühlenkamp, for så på sjettedagen, tirsdag d. 9. juni, at køre nordpå mod Tønder. Endnu en vellykket tur, den tiende i rækken af vore ekskursioner, var slut.

Den 9. september havde vi inviteret de lokalhistoriske foreninger i Tønder kommune til det årlige fællesmøde, hvor foreningerne fortæller om deres arrangementer i det forløbne år og hvad de har af planer for det kommende. Mødet var som sædvanligt godt besøgt med fremmøde fra 14 af de 16 inviterede lokalhistoriske foreninger. Christian Jacobsen fra Arrild lokalhistoriske forening viste rundt i Arrild Ferieby og fortalte om dens historie. Det blev en spændende fortælling om planlov, EU-midler, byudvikling, landskabspleje og kommunesammenlægning - om en tid med sprudlende optimisme i halvfjerdserne.

Carl Erik Michelsen

\section{Sydslesvig kreds}

I anledning af 60-året for de slesvigske mindretalserklæringer fra 1955 afholdt vi den 12. marts en debataften på Christian Paulsen Skolen med titlen København-Bonn erklæringerne - 60 år og hoad så? med fokus på erklæringernes aktuelle betydning. I debatpanelet medvirkede Grænseforeningens formand Mette Bock, MF, chefredaktør Jørgen Møllekær, Flensborg Avis og hans kollega Gwyn Nissen fra Der Nordschleswiger samt SSW-landssekretær Martin Lorenzen. Generalsekretær Jens A. Christiansen fra SSF var ordstyrer. Debatten og det efterfølgende kaffebord, der afholdtes i samarbejde med SSF, Dansk Skoleforening, Den Slesvigske Kvindeforening og Aktive Kvinder, samlede 62 deltagere.

Den 23. april holdt vi generalforsamling i Slesvig roklubs nye lokaler. Vi begyndte med en rundvisning ved formanden Birger Kühl. Efter generalforsamlingen fortalte museumsinspektør Nis Hardt fra Danevirke Museum om arkæologi i Slesvig.

Den 10. november stod kredsen for endnu et velbesøgt debatarrangement denne gang på Jaruplund Højskole. Temaet var Hvem og hvad er Det danske Mindretal i dag? Diskussionen tog udgangspunkt i den nyligt foretagne undersøgelse af mindretallet ved docent Adrian Schaeffler-Rollfs, MA fra Uni Hamburg. Undersøgelsens resultater blev efterfølgende kommenteret af rektor Jørgen Kühl, Slesvig, og dr.phil. Karen Margrethe Pedersen, Aarhus, tidligere Institu for Grænseregionsforskning ved Syddansk Universitet. Derefter blev debatten givet fri. Aftenen var arrangeret i samarbejde med Dansk Centralbibliotek, SSF og Folkeuniversitetet.

Kirsten la Cour

\section{Oversigt over årsskrifter og periodica 2015/2016}

\author{
Udgivet af de lokalhistoriske foreninger, museer \\ og arkiver 2015/2016.
}

Agerskov

Arsskrift 2016

Udgivet af Lokalhistorisk Forening for Agerskov sogn. 2016. 32 sider. Indhold: Hans Buhl: "Historien om Nulbjerg" - Asmus Clausen: "Genskrivning af artikel i "Dannevirke" 1953" - "Klara og Tinus fortæller" - "Udflugt" - "Bestyrelsen".

Ekspedition: Jens Lautrup, "Meldkjær", Overbyvej 4, Geestrup, 6520 Toftlund, tlf.: 404511 79, email: meldkjaer@mail.dk.

\section{Augustenborg}

Årsskrift 2016

Udgivet af Lokalhistorisk Arkiv for Augustenborg og Omegn. 2016. 40 sider. Indhold: Birte Tuesen: "Forord" - Jens Raben: "Brovold" - Hans Lind m.fl. "Kinderheim Sonnenschein" - Poul Krog: "Da Als og Ærø var et bispedømme" - Hans Lind: "Margrethe og Genforeningsfesten" - Peter Hess: "Fra høstens tid" - Birte Thuesen: "Det franske ur" - Max Hansen: "En gammel skik" - Jens Lampe: "Færgestedet ved Fynshav" - Rasmus Jensen: "Notmark krøniken Almsted" - Hans Lind: "En kvinde, der arbejdede i det stille" - Lisbeth Schou: "Skrivemaskinen".

Ekspedition: Lokalhistorisk Arkiv for Augustenborg og Omegn, Slotsallé 10, 6440 Augustenborg, tlf.: 744718 08, email: aug.larkiv@pc.dk

\section{Bevtoft og Tirslund}

Arsskrift 2016. Aktuelt fra arkivet

Udgivet af Lokalhistorisk Arkiv for Bevtoft og omegn. 2015. 29. årgang. 23 sider. Indhold: Carsten Christensen: "Ungdom i Hjartbro - Bevtoft i halvtresserne" - Peter Mortensen: "Det er længe siden. Erindringer fra min barndom i 1940'erne i Strandelhjørn" - Inger Lauridsen: "En sønderjysk familie mellem dansk og tysk" - "Årets gang i Bevtoft - Tirslund Lokalhistoriske Forening" "Minde om Jens Christensen" - "Ole Lindholdts Grundlovstale i Bevtofts præstegråd 2015".

Ekspedition: Lokalhistorisk Arkiv for Bevtoft og omegn, Bevtoft Skole, Krygersvej 45,6541 Bevtoft. 


\section{Bov og Holbøl sogne}

Historisk årbog for Bov og Holbøl sogne årgang 2015

Udgivet af Historisk Forening for Bov og Holbøl Sogne. Årgang 38. 2015. 76 sider. Indhold: "Forord" - Kim Furdal: "Kruså vandmølle et svært klenodie" - Rigmor Heiselberg: "Kylle i Kruså Forsamlingshus" - Ernst Christiansen "Mine forældre til ære - en beretning fra Kollund Bjerg" - Harry Petersdotter: "Højt skum på Flensborg Fjord" - Leif Kiesbye: "Det rene Klondike på Kollunds Molevej" - Leif Lindersgaard: "Padborglejren lant ud i skoven" - H.C. Jørgensen: "En svær plads ved Kollund" - Torben Ølholm: "En ildsjæl har fåe sin sten" - Kristian Jürgensen: "Hvor blev de mon af?" - H.C. Jørgensen: "Bov kirkelige sognekrønike en guldgrube" - "Årets hus" - Mads Mikkel Tørsleff "Nyt fra Oldemorstoft" - John Levin: "En udflugt ud i det blå" - John Levin "Året der gik i foreningen" - Jørgen Rasmussen: "Årets gang i Lokalarkivet" "Historisk årbog" - "Bestyrelsen i Historisk Forening for Bov og Holbøl Sogne". Ekspedition: Museum Sønderjylland, Oldemorstoft, Bovvej 2, 6330 Padborg tlf.: 746751 50, email: bov@museum-sonderjylland.dk

\section{Bredebro}

Æ Huulspor 2015

Udgivet af Lokalhistorisk Arkiv, Bredebro. 13 årg. 2015. 84 sider. Indhold: "Husk os" - "Forord" - "Årets glimt" - Brian Nesgaard: "Stadig midt i en globalisering" - "Glimt fra for 25 år siden i 1990" - "Jubilæumsåret på godt og ondt" - "Gammel Stine o hind flag" - "Magnus Thomsen - fra passiv til aktiv modstand i Bredebro og omegn" - Martin Thyssen: "En fortælling om min bedstemor" - Niels Henriksen: "En Slesviger krydser sit spor" - "Ballum Enge og Skast Mose blev afvandet" - Liv Øvlisen Brun Jensen: "Litteraturens rolle Sønderjylland 1864-1920"- Signe Beier Lønne: "Udvekslingsstudent i Colorado, USA" - Mette Larsen: "Guldkonfirmation" - "Årets udflugt" - "Bogliste 2015" - "Lokalhistorisk Arkiv" - "Bestyrelsen" -

Ekspedition: Sparekassen i Bredebro, Min købmand i Ballum og Lokalbrugsen i Visby.

\section{Egen}

Årsskrift 2015

Udgivet af Egen Sogns Lokalhistoriske Forening. 2015. 48 sider. Indhold: Henrik Skrydstrup: "Forord" - "Egenmølle kro" - "Soldaterskæbner 1914-1918" - "Familien Ebbesen Madsen" - "En tue e'gemmel min barndoms by" - "Vers af Deichgräber".

Ekspedition: Peter Petersen, Møllevej 6, 6430 Nordborg, tlf.: 74458236.

\section{Ensted}

\section{Årsskrift 2015}

Udgivet af Ensted Sogns Lokalhistoriske Forening. 2015. 64 sider. Indhold:

"Indholdsfortegnelse" - "Forord" - Günther Rossen: "Mit livs teatereventyr"

- "Det skete i 1915" - "Billeder" - "Det skete i 1965" - Martin Reimers: "Lytte- posten" - "Billeder" - "Krondiamantkonfirmation 2015" - "Guldkonfirmation" - "Årsberetning 2014-15" - "Foreningens bestyrelse - åbningstider".

Ekspedition: Niels Høj Rossen, Sdr. Hostrup Bygade 64, Sdr. Hostrup, 6200 Aabenraa, tlf.: 746133 57, email: biniro@mail.dk

Felsted

Historisk Årbog for Felsted Sogn 2015

Udgivet af Historisk Forening for Felsted Sogn. Nr. 33. 2015. 103 sider. Indhold: Sven Zachariassen: "Anlægsgartner Frank Sørensen - en iværksætterhistorie i Felsted" - Ejner Thaysen: "En landmandskone i Tumbøl, Metha Thaysen, 1901-1981" - Kai Eskildsen Møller: "Musiker og kromand i Felsted, Rasmus Møller" - Kai Eskildsen Møller: "Varetagelse af arbejdet ved kirker, skoler og fattigvæsenet i slutningen af 1700-tallet" - Dorte Holm Frandsen: "Mit Tråsbøl" - Dorte Holm Frandsen: "Mit Tråsbøl, 3 Tråsbøldrenges fortællinger fra 'det gamle Tråsbøl'" - Mit Tråsbøl, som jeg husker det" - Andreas Asmussen: "Landsbyen Tråsbøls historie" - Andreas Asmussen: "Gårde og kåd i Tråsbøl" - Lorenz Lorenzen: "Uddrag af Hejmdal 1915 for Felsted Sogn" - Lorenz Lorenzen: "uddrag af Hejmdal 1965 for Felsted Sogn" - Kai Eskildsen Møller "Christian Jesper Jespersen Ensted - en gårdmaler" - "Kai Eskildsen Møller: "Brændevinens gode egenskaber" - "Guldkonfirmation i Felsted kirke den 3. maj 2015" - Andreas Asmussen: "Set og sket i årets løb" - Kai Eskildsen Møller: "Foreningen - Arkivet - Patsches Hus".

Ekspedition: Andreas Asmussen, Kirkevej 2, Felsted, 6200 Aabenraa, tlf.: 7468 53 30, e-mail: asmussen@bbsyd.dk

\section{Gråsten}

Årsskrift 2015

Udgivet af Historisk Forening for Graasten by og egn. 2015. Nr. 41.56 sider Indhold: Gerd Conradsen: "Kværs hede - Kværs Plantage" - Jens Hansen og Lars Thiesgaard: "Interview med forhenværende politimester Aksel Bjerre" Hans Munk Hansen: "Æ Æbelhave og træplantage på gården 'Schønheim' i Rinkenæs". Gerd Conradsen: "En besynderlig historie fra Justitsprotokollen for Gråsten Gods" - Leif Hansen Nielsen: "Gråsten. En kommune under forandring 1970-2006" (anmeldelse) - Else Egholm: "Årets gang" - Bodil Gregersen: "Foreningens beretning" - Bodil Gregersen: "Æresmedlem" - Else Egholm: "Beretning fra arkivet" - "Bestyrelsen".

Ekspedition: Bodil Gregersen, Klokkevej 2, Rinkenæs, 6300 Gråsten, tlf.: 7465 31 81, email: bouf@post.tele.dk

Haderslev

Langs fjord og Dam. Lokalhistorie omkring Haderslev 2015

Udgivet af Forlaget Gammelting 2015. 113 sider. Indhold: Helge Wiingaard: »En højbåren jomfru, en ædel kongebrud « - Helge C. Jacobsen: »Ultanggård og Ultang Mølle« - Kaj Erik Andersen: »Min familie var aktiv i afholdsbevægelsen i Haderslev« - Mogens Asmund: »De første skal blive de sidste« - Lars 
Amenda: »Haderslev-Hamborg. Et tidligt og vigtigt cykelløb i Nordtyskland: 1894-1906« - Helge C. Jacobsen: »Det tyske mindretal i Haderslev efter 1945« Sven Borregaard: »Nis A. Jacobsens rejse 1915-1920« - Anja Usbeck Pedersen "Spadeslaget 8. december 1940« - Hans Vilhelm Bang: »Et frugtbart tiår i Haderslevs nyere historie.

Ekspedition: Museum Sønderjylland - Arkæologi Haderslev. Dalgade 7, Postboks 122, 6100 Haderslev, tlf.: 745275 66, haderslev@museum-sonderjylland.dk

\section{Hejls-Hejlsminde}

Jesper J. Schultz - en jernbaneingeniør fra Hejls i Kina. Årsskrift 2015

Udgivet af Lokalhistorisk Forening og Arkiv for Hejls-Hejlsminde 2015. 96 sider. Indhold: Gunnar Krag: "Slægten Schultz i Hejls ca. 1680-1920" - "Præsentation af Albert König" - Albert König: "Jesper Johansen Schultz (6.12.1865-15.11.1943)". Ekspedition: Gunnar M. Krag, Trappendalvej 29, 6094 Hejls, tlf.: 75574754. email: trappendal@profibernet.dk

\section{Hoptrup}

Hoptrup Sogns Lokalhistoriske forening 2015

Udgivet af Hoptrup Sogns Lokalhistoriske Forening. 32. årgang. 2015. 47 sider Indhold: Jens Knudsen: "Formandens beretning" - Margit Friborg: "Sønderjyske erindringer" - "Hoptrup Forsamlingshus" - "Udflugt 2016" - "For 100 år siden" - "For 75 år siden" - "For 50 år siden" - "For 25 år siden" - "Hoptrup Forsamlingshus" - Ove Ethelberg: "Faldne fra Hoptrup sogn i 1915" - Jørgen Lei: "Familien Lei fra Dundelum".

Ekspedition: Jørgen Hasberg, Kalmargårdparken 18, Marstrup, 6100 Haderslev, tlf.: 64576886 .

\section{Højer}

Højer Lokalhistoriske Forening 2016

Udgivet af Højer Lokalhistoriske Forening. 2016. 22 sider. Indhold: Jørn F. Petersen: »Året der gik « - Rosa Barfod: »En mor under besættelsen« - Jørn F. Petersen: »Højer Kirkes døbefont« - Jette Lausten: »Sognekrøniken for Emmerlev Sogn « - »Dengang man lavede sin egen strøm i Højer « - Jørn Petersen: »Da præsten skød på prædikestolen« - Hans Peter Wendicke: »Grænsehandel ved Rudbøl 1957 til 1968« - »Program 2016«.

Ekspedition: Jørn Frendesen Petersen, Ternholm 3, 6280 Højer, tlf.: 74782879 , email: dejbjerg@email.dk

\section{Hørup}

Lokalhistorisk Forening for Hørup Sogn. Årsskrift nr. 34 - 2016

Udgivet af Lokalhistorisk Forening for Hørup Sogn. 40 sider. Indhold: Karin Kaad, Mary Larsen og Bent Zachariassen: "Hist hvor vejen slår en bugt - historie om et hus" - Peter A. Christensen: "Bysamfundet Høruphav" - Chresten Wolf: "Havnen i Høruphav" - Christen Clausen: "Frygt for hestesygdom" Christen Clausen: "Mailbølgård kom i arvepagt 1744" - Hans Aa. J. Schmidt
"Da e Korre bløv Bombe (2)" - "Hørup Kirkeklokke stjålet i 1805" - "Hørup Kirke som krudtmagasin" - Kurt Philippsen: "Min vej til Hørup Centralskole (fortsat fra årsskrift nr. 33, 2015)" - Birthe Danielsen: "Året der gik - ifølge avisudklip" - Andreas Kaad: "Årets gang i lokalarkivet i kælderen på Hørup Skole" - "Sognet rundt (fortsat)" - Henning Popp: "Arkivet 2015" - "Generalforsamling 2016 med dagsorden".

Ekspedition: Bent Zachariassen, Skovhøj 47, 6470 Sydals, tlf.: 74415289.

\section{Jegerup}

Lokalhistorisk Forening for Jegerup Sogn 2015

Udgivet af Lokalhistorisk Forening for Jegerup Sogn. 2015. 36 sider. Indhold: "Roser ved Bygaden" - "Året 2015 i Lokalhistorisk Forening for Jegerup Sogn" - Ellen L. Petersen: "Jørgen Junkers stilehefte fra 1922" - Lisbeth Kærgaard Pedersen: "En uventet gæst" - Kaj Sandholdt: "Fattighuset" - Børge Hansen: "Her er vort liv" - Kaj Sandholdt: "Jes Brams barndomserindringer" - Knud Jensen: "Christian Schmidt, Adelvej 33" - Ole Aalling: "2 minutter til Mellemøsten" - Kaj Sandholdt: "Præstetavlen"

Ekspedition: Vojens Boghandel, Rådhuscentret 23, 6500 Vojens, tlf.: 27117955.

Kliplev

Fra Kliplev Sogn 2015. Lokalhistorisk Forening

Udgivet af Lokalhistorisk Forening for Kliplev Sogn. 2015. 79 sider. Indhold: "Forord ved formanden" - "Krigsdagbog - fortsat fra Årsskrift 2014" - "Klip fra Jydske Tidende 1965" - "Bjerndrup Husholdningsforenings 60 års jubilæum 1999" - "Huse i Kliplev, Storegade 29, 33, 16 (Kliplev Hovedgade)" - "Jernbanesabotør 1943-45. Om stationsmester Lorenz Jessen" - "Hitler-skæg" - "Klip fra Heimdal 1915" - "åbningstider, bestyrelse m.v.".

Ekspedition: Kaj Lassen, Holmvej 15, Kliplev, 6200 Aabenraa, tlf.: 746874 62, email: lassen@bbsyd.dk

\section{Løgumkloster}

Historisk Forening for Løgumkloster Kommune. Årsskrift 2016

Udgivet af Historisk Forening for Løgumkloster Kommune. 2016. 62 sider. Indhold: Allan Honoré: "Breaking News" - Niels T. Sterum: "Fra Judas Iskariot til Jakob den Ældre - en sengotisk træskulpturs forvandling" - Vagn Lauritzen: Ved en korsvej - om bebyggelsen Løgumbjerg" - "Afleveringer til arkivet, 2015".

Ekspedition: Vagn Lauritzen, Ved Dammen 56, 6240 Løgumkloster, tlf.: 747443 03, e-mail: vagn-lauritzen@mail.tele.dk

\section{Nordborg}

Årsskrift 2016

Udgivet af Lokalhistorisk Forening for Nordborg-området. 2016. 40 sider. Indhold: "Indhold" - Jens-Ove Hansen: "Forord" - "Redaktørens side" - "Peter Grau - et fyrtårn i grænselandskampen" - "Efterårets bogudgivelser" - "Min- 
deord over Jens H. Møller og Erik Manthei Nielsen" - "Billedeksempler fra efterårets bog".

Ekspedition: Hans Jørgen Berg, Skovvej 14, 6430 Nordborg, tlf.: 74451058 , email: famberg@berg.mail.dk

\section{Rens}

Historisk årbog 2013

Udgivet af Rens \& Omegns Lokalhistoriske Forening. 2013. 56 sider. Indhold: "Forord" - Karen Marie Jensen: "'Lille Jensen' Gendarm Karl Otto Jensen, Lille Jyndevad" - Knud Erik Gehrt: "Kongebesøget i Rens - 1934" - Karin Sofia Gehrt: "Fra Finland til Rens Hedegård" - Tove Hansen: "Glimt fra min barndom i Store Jyndevad" - Svend Petersen: "Uden Rens-Lokalhistorie var vi aldrig kommet videre" - Kitta og Svend Petersen: "Peter Kühner - en kolonist" - Knud Erik Gehrt: "Landsbyidyl i Store Jyndevad (1966)".

Historisk årbog 2014

Udgivet af Rens \& Omegns Lokalhistoriske Forening 2014. 76 sider. Indhold: Ruth Christensen: "Forord" - Andreas Ruhlmann: "Restaureringen af Burkal Kirke" - Georg Hansen: "Georg Hansen fortæller" - Adolf Muus: "Rens Mejeri og Mølle" - Kitta og Sven Petersen: "De, der aldrig kom hjem" - Lorenz Hansen: "Jyndevad forsøgsstation" - Ruth Christensen og Jens Chr. Jensen: "Huse, der er forsvundet fra bybilledet" - "Bestyrelsen".

\section{Historisk årbog 2015}

Udgivet af Rens \& Omegns Lokalhistoriske Forening 2015. 71 sider. Indhold: Ruth Christensen: "Forord" - "Bestyrelsen" - Ruth Christensen: "Vraagaard" Erik Pedersen: "Jyndevad Mølle. Vandmøllen ved Sønderåen" - Kitta og Sven Petersen: "De, der aldrig kom hjem" - Jens Chr. Jensen: "Historisk rids og erindringer fra Rens" - Gabi Andresen: "Interview med Nis Andresen" - Johs. Johannsen: "Æ bokmøll snakker med".

Ekspedition: Rens \& Omegns Lokalhistoriske Forening, Pebersmarkvej 4, 6372 Bylderup-Bov, e-mail: rens@rens-lokalhistorie.dk

\section{Rodding}

Historisk Årbog fra Rødding-egnen 2015

Udgivet af de lokalhistoriske arkiver, foreninger og udvalg i den "gamle" Rødding Kommune. 2015. 120 sider. Indhold: "Forord" - M. Mackeprang: "Honnet Ambition eller Naar Damer fører Krig" - Mogens Lorentsen: "Toldergården Foldingbro" - Kaj Frandsen: "Da æ Kleinbahn kom til Øster Lindet" - Kirsten Rosendahl: "Mariegård ved Jels Sø" - Marita Kreienbring: "Venskab i generationer - trods krige og grænser" - Valborg Hansen: "Frans Rist" - Arne Juhl "Forbrændte brandmænd" - Ingrid Jensen: "Ole Gotveds livshistorien" - Niels Chr. Andersen: "Nej til antenneskov i Rødding" - John Ipsen: "Jens Ipsen, Sdr. Hygum - hans tid i Fremmedlegionen og Royal Air Force" - "Lokalhistoriske arkiver, foreninger og udvalg".
Ekspedition: Rødding Lokalhistoriske Arkiv, Søndergyden 15, 6630 Rødding, tlf.: 799656 65, e-mail: roeddingarkivet@hotmail.com

\section{Rødekro}

Lokalhistorisk Forening Rødekro 2015

Udgivet af Lokalhistorisk Forening i Rødekro. 2015. 160 sider. Indhold: "Foreningens bestyrelse og udvalg" - "Afleveringer til arkivet 2013" - "Året 20142015" - "Muligheder for søgning af billeder på arkiv.dk" - Verner Sieger: "Fra Duka-lakering til autolakering i Rødekro" - Terkel Petersen: "24 år i Ørslev" - Agnes Elisabeth Pedersen: "Fra stilehefte: Min skoletid" - Hans H. Toft: "En kommune blev til" - Ingrid Nissen: "Hejmdal for 100 år siden" - Johannes Jessen: "Bomber over Sønder Ønlev" - Hans Chr. Clausen: "Erindringer og oplevelser" - "Uddrag af poesibog" - Ingrid Nissen: "En rejse til Affenraa" - Egon Kaas: "Alle oplysninger er fra Jydske Tidende i 1965" - Ingrid Nissen: "Immervad Bro" - Egon Kaas: "Min skoletid" - Hans Michelsen: "Rise en landsby" - Peter Høier: "Kommunalt arbejder" - Ole Edward Mogensen: "Rødekro station" - Bjarne Andresen: "Magge Slawter fra Rødekro" - "Harry Nielsen Dall" - Robert Hjed Christensen: "Fra mine barndomsår i Rødekro" - "Livsvarig aftægt" - Peter Høier: "Erindringer" - Hans Michelsen: "Ejendomme på Rise Bygade" - Frederik Kolmos: "Sparevise".

Ekspedition: Rødekro Boghandel, Østergade 3, 6230 Rødekro, tlf.: 74661077.

\section{Sundeved}

Skrift for Lokalhistorisk Forening for Sundeved 2015

Udgivet af Lokalhistorisk Forening for Sundeved. 2015. 94 sider. Indhold: Nuværende bestyrelse for Lokalhistorisk Forening for Sundeved" - "Mindeord, Kathe Sørensen, Verner Brodersen og Louise Schulz" - Birthe Solmer: "Jes L. Solmers erindringer" - Musse Fenn-Hansen: "Hans Peter Petersens skudsmålsbog" - Peter J. Brodersen: "Hændelser og data om skoler i Blans 1684 til 1962" - H. Petersen: "Sorrig og glæde" - Carl Peter Møller: "På det første rekruthold med sønderjyder siden 1864" - Asta Flyvholm Kjær: "Bosse'o andt gotfolk!" John Solkær: "Lokalhistorisk Arkiv i nye rammer" - "Året der gik 2014".

Ekspedition: Lokalhistorisk Arkiv, Truenbrovej 21 A, Avnbøl, 6400 Sønderborg, tlf.: 744661 05, e-mail: sundevedarkiv@gmail.com

\section{Toftlund}

Toftlund Lokalhistoriske Forening. Årsskrift 2016. årgang 10

Udgivet af Toftlund Lokalhistoriske Forening. Årgang 10. 2016. 64 sider. Indhold: "Forord" - "Mindeord" - CEC: "Han blev fornærmet og gik rettens vej" - LM: "Et rigt liv med arbejde og familie" - "Gæster på arkivet 30. september 2015" - Lis Mikkelsen (red.): "Der har altid været masser af arbejde og mange børn" - "Et dejligt legested" - Jens Jørgen Laursen: "Verden er stor" - CEC: "En danskers ansættelse i Tyskland" - LM: "Bondegårdsferie" - "Billede fra det gamle Stenderup" - LM: "En usædvanlig sangskjuler" - LM: "Alle de engelske 
ord!" - LM: "Beboerne på Storvig" - Sine Hansen: "40 år på plejehjem" - LM: "Mogens Holst Knudsen" - "Nyt på arkivet" - "Bestyrelsen for Toftlund Lokalhistoriske Forening".

Ekspedition: Anne-Grethe Petersen, Mariavænget 9, 6520 Toftlund, 748322 34/20 259513 email: agp@toftlund.net

\section{Tønder}

Tønder-erindringer XVI. Lokalhistorisk Forening for Gl.-Tønder Kommune. 2015

Udgivet af Lokalhistorisk Forening for Gl.-Tønder Kommune 2015. 48 sider Indhold: Eddie Carstensen: "Børnenes Paradis i Tønder" - Knud Madsen "Seminarielærer Claus Eskildsens deltagelse i 1. Verdenskrig" - Holger Rasmussen: "Hvad pokaler kan fortælle" - Jørn Vestergaard: "Min tid blandt sortekunstens svende" - Verdenskrig" - Holger Rasmussen: "Hvad pokaler kan fortælle" - Jørn Vestergaard: "Min tid blandt sortekunstens svende" - Pou Raaby Pedersen: "Svinget - røddernes barndom u' i $æ$ Lejr" - Thomas Selmer: "3 generationer i træets verden" - "Indholdsfortegnelser".

Ekspedition: Lokalhistorisk Forening og Arkiv for Gl.-Tønder Kommune, Richtsensgade 10, 6270 Tønder, tlf.: 747233 26, email: mail@lha-toender.dk

\section{Vojens}

Årbog 2015 for Lokalhistorisk Forening for Vojens-området. 29. årgang

Udgivet af Lokalhistorisk Forening for Vojens-området. 29. årgang. 2015. 67 sider. Indhold: "Forord" - Knud Schmidt Petersen: "Optegnelser fra en bevæget tid" - Erik Christensen: "Dora von Manteuffel - en adelsfrue i Vojens" - "Noter fra aviser. For 75 og 100 år siden" - "Bakken gav hvile efter 5 onde år" - Agnes Svendsen: "Gavle: Dybbølgade" - Sven Stuhr: "Flyveangreb på Vojens Station, 1945" - Peter Rasmussen: "Mølleri gennem 6000 år" - Agnes Svendsen "Kyhls Vej, Skovby" - Johannes Jespersen: "Erindringer: Margarethe Schmidt, født Lykke" - Jens Peter Gram: "Hans Gram, Skrydstrupmark" - Niels Munch Christensen: "Lokomotiver på Vestergade i 1945" - "Navneliste over faldne Vedsted Sogn i 1. Verdenskrig" - "Navneliste over faldne i Hammelev Sogn 1. Verdenskrig" - Helge C. Jacobsen: "Arkitekt Julius Hallenberg" - Chr. Mortensen: "Betragtninger over vor Families indsats gennem fire Generationer Kampen mellem Tysk og Dansk" - Agnes Svendsen: "Mindeord Laurids Lund" - Preben F. Nørup: "Foreningens virke 2015" - Agnes Svendsen: "Årets gang på Arkivet i 2015" - "Adresseliste m.m. for Lokalhistorisk Forening for Vojensområdet".

Ekspedition: Preben F. Nørup, Kædevænget 1, 6500 Vojens, tlf.: 745416 02, email: noerupsenior@gmail.com

\section{Vonsbæk}

Lokalhistorisk Forening for Vonsbæk Sogn. Årsskrift 11. årgang 2015

Udgivet af Lokalhistorisk Forening for Vonsbæk Sogn 11. årgang 2015. 27 sider Indhold: "Formanden har ordet" - "Efterlysning" - "Det stod i avisen" - Holger Eskildsen: "Generalforsamlingen d. 18. marts 2015" - "Første Verdenskrig"
- "Notater i 'Dannevirke 1915" - "Overlevende fra 1. Verdenskrig" - "Indkaldelse til krig. 1. Verdenskrig. Min bedstefar Peter Aarøe" - Peter Aarøe: "2. Verdenskrig. Min far Søren Lausen Aarøe" - "Breve fra 1. verdenskrig skrevet af Knud Nielsen til hans kone Anna, Ørbyhage" - "Det skete for 100 år siden. Dannevirke 1915" - "Pædagogen" - "Plantning af Valgtræ ved Vonsbæk Skole". "Glimt fra 2015".

Ekspedition: Holger K. Eskildsen, Kildager 30, Bæk, 6100 Haderslev, tlf.: 7457 91 10, email: he9110@gmail.com

Øster Lindet

Glimt. Fra Øster Lindet sogns historie, nr. 29, 2015

Udgivet af Lokalhistorisk Forening for Øster Lindet sogn, nr. 28, 2014, 24 sider. Indhold: Jørn Frank: »Træk fra min barndom og ungdom i Rojbøl « - Frode Rindom: »Fra avisudklip 1956 og 1957« - »Forening og arkiv«.

Ekspedition: Kaj Frandsen, Villavej 13, Øster Lindet, 6630 Rødding, tlf.: 7484 6106.

\section{Aabenraa}

Historier fra Bybakken. Årsskrift for Aabenraa Byhistoriske Forening 2015

Udgivet af Aabenraa Byhistoriske Forening i samarbejde med Museum Sønderjylland - ISL. 2015. 85 sider. Indhold: Lars N. Henningsen: "Aabenraa på revolutionstiden - Inficeret af Pariserluft?" - Erik Housted: "Englandskrigenes kystbatterier i Aabenraa" - Manfred Federau: "Trange Kår. Livet i 'Æ Stenbarakke' i Aabenraa under og efter anden verdenskrig" - Erik Jakob Petersen: "Set fra trappestenen - flere småglimt fra drengetiden i 1940-47" - C. Gamborg: "Ungdomsminder fra 1848".

Ekspedition: Bog og Idé, Ramsherred 28, 6200 Aabenraa, tlf.: 74622229. 